\title{
Mechanisms underlying the transport and intracellular metabolism of acetic acid in the presence of glucose in the yeast Zygosaccharomyces bailii
}

\author{
Maria João Sousa, Fernando Rodrigues, Manuela Côrte-Real \\ and Cecília Leão
}

Author for correspondence: Cecília Leão. Tel: +351 53 604311. Fax: +35153678980.
e-mail : cleao@bio.uminho.pt

Department of Biology, University of Minho, 4719 Braga Codex, Portugal

\begin{abstract}
Zygosaccharomyces bailii ISA 1307 displays biphasic growth in a medium containing a mixture of glucose $(0.5 \%, w / v)$ and acetic acid $(0.5 \%, w / v)$, pH 5.0 and 3.0. In cells harvested during the first growth phase, no activity of a mediated acetic acid transport system was found. Incubation of these cells in phosphate buffer with cycloheximide for $1 \mathrm{~h}$ restored activity of an acetic acid carrier which behaved as the one present in glucose-grown cells. These results indicated that the acetic acid carrier is probably present in cells from the first growth phase of the mixed medium but its activity was affected by the presence of acetic acid in the culture medium. In glucose-grown cells, after incubation in phosphate buffer with glucose and acetic acid, the activity of the acetic acid carrier decreased significantly with increased acid concentration in the incubation buffer. At acid concentrations above $16.7 \mathrm{mM}$, no significant carrier activity was detectable. Furthermore, the intracellular acid concentration increased with the extracellular one and was inversely correlated with the activity of the acetic acid carrier, suggesting the involvement of a feedback inhibition mechanism in the regulation of the carrier. During biphasic growth, the first phase corresponded to a simultaneous consumption of glucose and acetic acid, and the second to the utilization of the remaining acid. The enzyme acetyl-CoA synthetase was active in both growth phases, even in the presence of glucose. Activity of isocitrate lyase and phosphoenolpyruvate carboxykinase was found only in acetic-acidgrown cells. Thus it appears that both membrane transport and acetyl-CoA synthetase and their regulation are important for $Z$. bailii to metabolize acetic acid in the presence of glucose. This fact correlates with the high resistance of this yeast to environments with mixtures of sugars and acetic acid such as those often present during wine fermentation.
\end{abstract}

Keywords: Zygosaccharomyces bailii, yeast, acetic acid transport, metabolism

\section{INTRODUCTION}

Zygosaccharomyces bailii is one of the most widely represented spoilage yeast species in food and beverages, being able to survive under various stresses and environmental conditions. One of the peculiar traits of this species is the mechanism underlying the transport of acetic acid into the cell and its regulation, the first step of acid metabolism. Previous results described in Z. bailii ISA 1307 have shown that cells grown in a medium with acetic acid, ethanol or glycerol as the sole carbon and energy source transported acetate by a saturable transport system. This system also accepted propionic and formic acids, but not lactic, sorbic or benzoic acids. When the carbon source was glucose or fructose, the cells displayed activity of a mediated transport system specific for acetic acid, apparently not being able to recognize other monocarboxylic acids (Sousa et al., 1996). This is in contrast to what has been described so far in other yeasts, namely Saccharomyces cerevisiae, 
Candida utilis and Torulaspora delbrueckii, where active transport of acetate is inducible and subject to glucose repression (Cássio et al., 1987, 1993; Casal \& Leão, 1995; Leão \& van Uden, 1986). Such differences displayed by $Z$. bailii have been related to the high resistance of this yeast to acidic media containing ethanol (Sousa et al., 1996).

In the present work, particular attention was given to the mechanisms underlying the utilization of acetic acid in the presence of glucose by the strain Z. bailii ISA 1307. Evidence is provided indicating that control of membrane transport of acetic acid and acetyl-CoA synthetase activity contributes to the high resistance of $Z$. bailii to environments containing mixtures of sugars and acetic acid.

\section{METHODS}

Micro-organism and growth conditions. Zygosaccharomyces bailii ISA 1307 was maintained in medium containing glucose $(2 \%, \mathrm{w} / \mathrm{v})$, peptone $(1 \%, \mathrm{w} / \mathrm{v})$, yeast extract $(0.5 \%, \mathrm{w} / \mathrm{v})$ and agar $(2 \%, \mathrm{w} / \mathrm{v})$. Cells were grown at $26^{\circ} \mathrm{C}$ in $2000 \mathrm{ml}$ shake flasks (160 r.p.m.) containing $1000 \mathrm{ml}$ mineral medium with vitamins (van Uden, 1967) supplemented with the carbon sources indicated in Results.

Measurement of initial uptake rates. For estimation of initial uptake rates, cells were harvested at exponential growth phase, or as indicated in Results, centrifuged, washed twice and suspended in ice-cold distilled water to a final concentration of $30-40 \mathrm{mg}$ dry weight $\mathrm{ml}^{-1}$. Uptake rates were measured by the use of $\left[\mathrm{U}^{-14} \mathrm{C}\right]$ acetic acid. For their estimation, $10 \mu \mathrm{l}$ amounts of yeast suspension were mixed in $10 \mathrm{ml}$ conical tubes with $30 \mu \mathrm{l} 0 \cdot 1 \mathrm{M} \mathrm{KH}_{2} \mathrm{PO}_{4}$ buffer at the desired $\mathrm{pH}$ value. After $2 \mathrm{~min}$ incubation in a water bath at $25^{\circ} \mathrm{C}$, the reaction was started by the addition of $10 \mu$ l of an aqueous solution of the labelled acid at the desired concentration and $\mathrm{pH}$ value. Reactions were stopped after 0,5 and $10 \mathrm{~s}$ by diluting with $5 \mathrm{ml}$ ice-cold distilled water. Sampling times for cells from the first phase of growth in the mixed medium were 30 and $60 \mathrm{~s}$. After stopping the reaction, the mixtures were immediately filtered through GF/C filters (Whatman), then the filters were washed with $10 \mathrm{ml}$ ice-cold distilled water and counted in the scintillation fluid OptiPhase HiSafe II (LKB Scintillation Products). Radioactivity was measured with a Packard TriCarb 2200 CA liquid scintillation counter, with correction for d.p.m. Results were corrected by subtracting for non-specific adsorption of labelled acid to the filters and/or the cells determined by diluting the cells with $5 \mathrm{ml}$ ice-cold distilled water before the addition of labelled acid $(0 \mathrm{~s})$. The values estimated for $0 \mathrm{~s}$ represented less than $5 \%$ of the total incorporated radioactivity.

To study the effect of extracellular acetic acid on the activity of the acetic acid transport system in glucose-grown cells, suspensions of these cells, prepared as described above, were suspended in $100 \mathrm{ml} 0 \cdot 1 \mathrm{M} \mathrm{KH}_{2} \mathrm{PO}_{4}$ buffer (pH 5.0) containing glucose $(0.25 \%, \mathrm{w} / \mathrm{v})$ and acetic acid $(0-83 \mathrm{mM})$ to a final concentration of $0.3-0.6 \mathrm{mg}$ dry weight $\mathrm{ml}^{-1}$. After incubation at $26^{\circ} \mathrm{C}$ with shaking for different time periods, samples were taken, and yeast suspensions were obtained, as described above, for measuring the uptake of labelled acetic acid.

Estimation of glucose and acetic acid concentration. Glucose and acetic acid concentrations in the media were assayed by HPLC, using a Refractive Index detector and a Polyspher OA
KC (Merck) column. Arabinose was used as an internal standard.

Estimation of intracellular acetic acid concentration. For determination of intracellular acetic acid content, cells were centrifuged, washed twice with ice-cold distilled water, and concentrated in a pellet $(12-15 \mathrm{mg}$ dry weight) by centrifugation. The pellet was extracted with $100 \mu \mathrm{l} 5 \%(\mathrm{v} / \mathrm{v})$ trichloroacetic acid for $45 \mathrm{~min}$ (twice) and the acetic acid concentration in the extracts was assayed as described above. Pyruvate was used as an internal standard. The intracellular concentration of acetic acid was calculated assuming that $1 \mathrm{mg}$ (dry weight) of yeast contained $1 \cdot 1 \mu \mathrm{l}$ intracellular water (Sousa et al., 1996).

Calculations of concentrations of carboxylic acid forms. Concentrations of undissociated and ionized forms of acetic acid were calculated using the Henderson-Hasselbalch equation with a $\mathrm{pK}$ value of $\mathbf{4 \cdot 7 6}$.

Enzyme assays. For enzyme assays, yeast cells were harvested in the mid-exponential phase of growth, washed twice with ice-cold distilled water and stored at $-70^{\circ} \mathrm{C}$. Cell-free extracts were prepared as described by Perea $\&$ Gancedo (1982), with modifications. Briefly, $30 \mathrm{mg}$ cells (wet weight) was mixed with $0.75 \mathrm{~g}$ glass beads $(0.5 \mathrm{~mm}$ diameter $)$ and $0.5 \mathrm{ml} 20 \mathrm{mM}$ imidazole buffer $(\mathrm{pH} \mathrm{7.0})$ and vortexed for four periods of $1 \mathrm{~min}$, with $1 \mathrm{~min}$ interval in ice between them. For cells harvested from media with glucose, the periods of vortexing were increased to eight. After centrifugation at $15000 \mathrm{~g}$ for $15 \mathrm{~min}$ at $4^{\circ} \mathrm{C}$, enzyme activities were measured in the supernatant. Enzymes were assayed following described procedures: phosphoenolpyruvate carboxykinase (Perea \& Gancedo, 1982); acetyl-CoA synthetase (Postma et al., 1989); isocitrate lyase (Huismank \& Hansen, 1982); and malate dehydrogenase (Witt et al., 1966). To increase the stability of acetyl-CoA synthetase, $\mathrm{MgCl}_{2}(2 \mathrm{mM})$ and DTT $(1 \mathrm{mM})$ were included in the extraction buffer as described by van den Berg et al. (1996). In all cases, one unit of enzyme activity was defined as the quantity of enzyme catalysing the conversion of $1 \mu \mathrm{mol}$ substrate $\mathrm{min}^{-1}$ under the assay conditions used.

Calculation of kinetic parameters of acetyl-CoA synthetase. The experimental data points from the initial reaction rates of acetyl-CoA synthetase in cells grown in glucose-acetic acid medium (first phase) were analysed according to Furhman \& Völker (1992) by a computer-assisted non-linear regression analysis using the GraphPAD computer program (San Diego, CA, USA). The best-fitting enzyme kinetics to experimental, initial reaction rate values were achieved and then estimates of the kinetic parameters were obtained.

Chemicals. Radioactively labelled acetic acid was obtained from Amersham with the following specific activity: [U${ }^{14} \mathrm{C}$ ] acetic acid, sodium salt, $2.2 \times 10^{9} \mathrm{~Bq} \mathrm{mmol}^{-1}$. All other chemicals were reagent grade and obtained from commercial sources.

Reproducibility of the results. All the experiments were repeated at least three times, and the data reported are mean values.

\section{RESULTS AND DISCUSSION}

Acetic acid transport systems and their regulation in cells of $\boldsymbol{Z}$. bailii grown in glucose-acetic acid medium

Growth of Z. bailii ISA 1307 in a medium containing glucose $(0.5 \%, \mathrm{w} / \mathrm{v})$ and acetic acid $(0.5 \%, \mathrm{w} / \mathrm{v})$, pH $5 \cdot 0$, was biphasic (Fig. 1). In these cells, when 


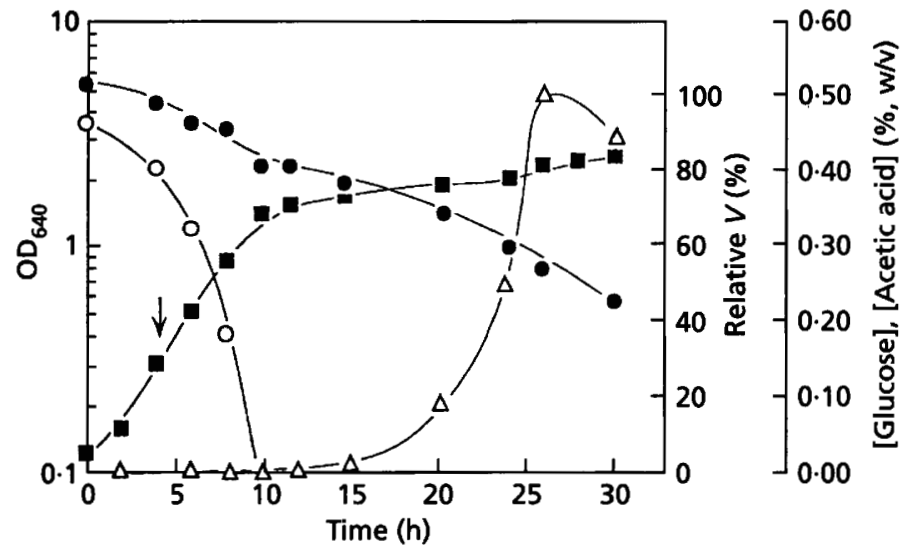

Fig. 1. Growth of Z. bailii ISA 1307 at $\mathrm{pH} 5 \cdot 0$ in a medium containing glucose $(0.5 \%, w / V)$ and acetic acid $(0.5 \%$, w/v). Relative $V$, activity values of the acetate carrier measured at a concentration of $12 \mathrm{mM}$ labelled acetic acid (pH 5.0) and expressed as a percentage of the highest value found during growth. At the time indicated by the arrow, cells were harvested for estimating intracellular acetic acid concentration. $O D_{640} ; O$, glucose; $O$, acetic acid; $\triangle$, relative $V$.

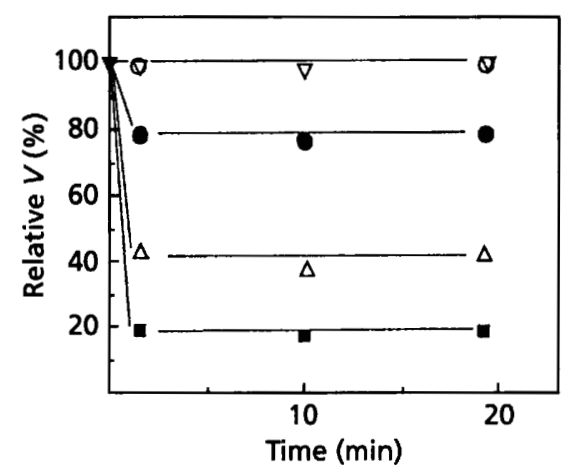

Fig. 2. Relative activity of acetic acid transport measured at $\mathrm{pH} 5.0$ at a concentration of $12 \mathrm{mM}$ labelled acetic acid in glucose-grown cells of $Z$. bailii ISA 1307 before $(\boldsymbol{\nabla})$ and after incubation in buffer $(\mathrm{pH} 5.0)$ with glucose $(0.25 \%, w / v)$ and acetic acid at final concentrations $(\mathrm{mM})$ of $0.0(0), 0.083(\nabla)$, $0.83(O), 8.33(\triangle)$ and $16.7(\square)$. Relative values were estimated considering activity values of the cells incubated in the absence of acetic acid to be $100 \%$.

transport was measured with labelled acetic acid, activity of a mediated transport system was found only after glucose had been consumed (Fig. 1). The kinetic parameters and the substrate specificity of this carrier were similar to those of the acetate-propionate-formate carrier previously reported for acetic-acid-grown cells (Sousa $e t$ al., 1996). Cells from the first growth phase, besides not revealing activity of this mediated transport system, did not display activity of the carrier specific for acetic acid described in cells grown in glucose medium (Sousa et al., 1996). Instead, initial uptake rates of labelled acetic acid were relatively insignificant when compared with those found for the two mediated transport systems. Furthermore, in the first growth phase, linear kinetics, indicating simple non-mediated diffusion, were observed (not shown) with a relatively low value for the diffusion constant $\left[0.0224 \mu \mathrm{l} \mathrm{s}^{-1}(\mathrm{mg}\right.$ dry wt cells) ${ }^{-1}, \mathrm{pH} 5 \cdot 0$ ]. This value is of the same order of magnitude as that estimated for the simple diffusion found in addition to the acetic acid carrier in glucosegrown cells under the same experimental conditions (Sousa et al., 1996). However, incubation of those cells (first phase) in phosphate buffer with cycloheximide $(0.01 \%, w / v)$ for $1 \mathrm{~h}$ restored activity of an acetic acid carrier which behaved as the one present in glucosegrown cells, concerning the specificity and kinetic parameters. Since cycloheximide is an inhibitor of protein synthesis in Z. bailii ISA 1307 (results not shown), the results indicated that the acetic acid carrier was probably present in cells during the first growth phase in the mixed medium but its activity was affected by the presence of acetic acid in the medium.

In the light of these results, the role of acetic acid in regulation of its transport system was investigated further. Glucose-grown cells were incubated for different periods of time in phosphate buffer with glucose in the absence and presence of acetic acid and, after washing, these cells were used for analysis of acetic acid transport activity. Fig. 2 shows that activity of the carrier decreased significantly with increasing acid concentration, the effect starting at concentrations as low as $0.83 \mathrm{mM}$. For all acid concentrations, the decline of the transport capacity occurred abruptly; less than 3 min being sufficient for the observed effect. At concentrations of acetic acid above $16.7 \mathrm{mM}$ no significant carrier activity was detectable. Activity in these cells was restored when incubated in buffer with cycloheximide $(0.01 \%, w / v)$ for $1 \mathrm{~h}$ (results not shown). The results indicated that the observed recovery of the carrier activity did not depend on de novo protein synthesis.

From these results it was tempting to postulate that the intracellular concentration of the acid could play a role in the observed loss of the acetic acid transporter capacity. In this context, the intracellular acetic acid concentration as well as the initial uptake rate of the acid were measured in glucose-grown cells incubated in the presence of different extracellular acetic acid concentrations (Fig. 3). These results showed that the intracellular concentration of acetic acid increased with the extracellular one and was inversely correlated with the initial uptake rate of the acid. In addition, cells from the first phase of the mixed-substrate medium, lacking the apparent capacity for transporting acetic acid, had a high intracellular acid concentration $(117 \mathrm{mM})$, whereas cells displaying acetic acid transport activity (glucose- or 


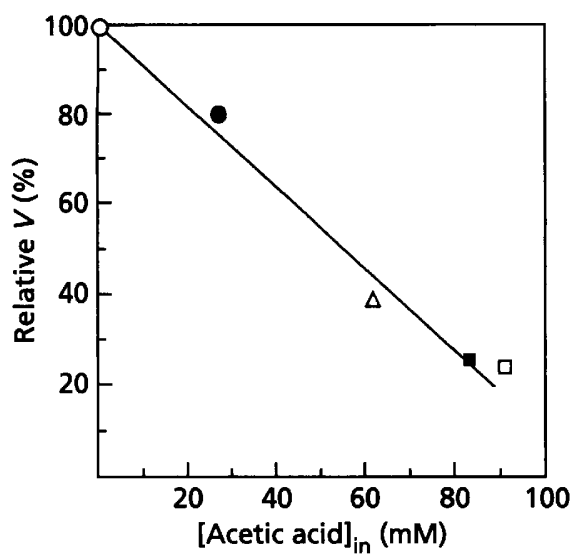

Fig. 3. Dependence of the relative activity of acetic acid transport on the intracellular acetic acid concentration. The activity of acetic acid transport was measured at $\mathrm{pH} 5.0$ at a concentration of $12 \mathrm{mM}$ labelled acetic acid in glucose-grown cells of $Z$. bailii ISA 1307 after $40 \mathrm{~min}$ incubation in buffer (pH 5.0) containing acetic acid at final concentrations (mM) of $0.0(0), 0.83(0), 8.33(\triangle), 16.7(\square)$ and $33.4(\square)$. Relative values were estimated considering the activity values for acetic acid transport obtained in cells incubated without acetic acid to be $100 \%$.

acetic-acid-grown cells) had a much lower value, about 50-230-fold less (Table 1). Hence such lack of measurable acetic acid transport is probably due to the high concentration of acetic acid inside the cell. This behaviour appears to be somehow similar to a feedback inhibition mechanism such as that described for the transport of amino acids and pyridine nucleosides in $S$. cerevisiae (Horák, 1986; Grenson, 1992).

\section{Simultaneous consumption of glucose and acetic acid by $Z$. bailii}

During the first phase in glucose-acetic acid medium (pH 5.0), growth was associated with the disappearance of both glucose and acetic acid from the medium (Fig. 1).
After the sugar had been exhausted, a second phase occurred corresponding with the exclusive assimilation of the acid. In cells harvested from the first growth phase, a value of about $117 \mathrm{mM}$ was estimated for the intracellular acetic acid concentration at $\mathrm{pH} 5.0$ (Table 1). This value was much lower than that expected theoretically by the accumulation of the acid by simple diffusion if neither acid metabolism nor the efflux of the anion were occurring (at the experimental $\mathrm{pH}$, an accumulation ratio of about $1: 100$ would be expected). The hypothesis of the efflux of the anion could not explain per se such an intracellular acid concentration since, at the time cells were harvested, a decrease of $0.026 \%(4.3 \mathrm{mM})$ acetic acid had occurred in the culture medium (see Fig. 1). If acid metabolism was not occurring and taking into account the corresponding biomass (Table 1), one would expect a significantly lower value for such an extracellular acid decrease (about $0.00029 \%$ ). Hence the results seem to indicate that, in Z. bailii, the intracellular metabolism of acetic acid is not subject to glucose repression, the acid being metabolized simultaneously with glucose.

When growth of $Z$. bailii was carried out in glucoseacetic acid medium at $\mathrm{pH} 3.0$, a behaviour similar to that described at $\mathrm{pH} 5.0$ was observed (Table 1).

\section{Enzyme activities in cells of $Z$. bailii grown in glucose-acetic acid medium}

During growth in the mixed-substrate medium, cells harvested from each of the exponential growth phases were used to determine the activities of key enzymes in metabolic pathways involved in the utilization of acetic acid. The enzymes selected were acetyl-CoA synthetase, isocitrate lyase, malate dehydrogenase and phosphoenolpyruvate carboxykinase. The activities of these enzymes were also determined in cells grown in media with glucose or acetic acid as the only carbon and energy source (Table 2). Acetyl-CoA synthetase was present under all growth conditions tested. However, the activity of this enzyme was much lower in cells grown in

Table 1. Intracellular acetic acid concentrations in cells of $Z$. bailii ISA 1307 grown with different carbon sources, and the biomass concentration present at the time cells were harvested in each of the different culture media

\begin{tabular}{|c|c|c|c|c|}
\hline \multirow[t]{2}{*}{ Carbon source } & \multicolumn{2}{|c|}{$\begin{array}{l}\text { Intracellular acetic acid } \\
\text { concn (mM) }\end{array}$} & \multicolumn{2}{|c|}{$\begin{array}{l}\text { Biomass concn } \\
\text { (mg dry wt } \mathrm{ml}^{-1}\end{array}$} \\
\hline & $\mathrm{pH} 3 \cdot 0$ & pH 5.0 & pH 3.0 & pH 5.0 \\
\hline $\begin{array}{l}\text { Glucose }(0.5 \%, \mathrm{w} / \mathrm{v}) \text { plus } \\
\text { acetic acid }(0.5 \%, \mathrm{w} / \mathrm{v})^{*}\end{array}$ & $159 \cdot 0 \pm 2 \cdot 9$ & $117 \cdot 0 \pm 1 \cdot 00$ & $0.48 \pm 0.0024$ & $0.38 \pm 0.090$ \\
\hline Glucose $(2 \%, w / v) \dagger$ & ND & $2 \cdot 4 \pm 0 \cdot 20$ & ND & $1.30 \pm 0.059$ \\
\hline Acetic acid $(0.5 \%, \mathrm{w} / \mathrm{v}) \dagger$ & ND & $0.5 \pm 0 \cdot 10$ & ND & $0.51 \pm 0.025$ \\
\hline
\end{tabular}

ND, Not determined.

* Cells were harvested in the mid-exponential phase of growth at the time indicated by the arrow in Fig. 1.

†Cells were harvested in the mid-exponential phase of growth. 
Table 2. Comparison of the specific activities of acetyl-CoA synthetase (ACS), isocitrate lyase (ICL), malate dehydrogenase (MDH) and phosphoenolpyruvate carboxykinase (PEPCK) in cell-free extracts of $Z$. bailii ISA 1307 grown at pH 5.0 with different carbon sources

Specific activities are expressed in $\mathrm{U}$ (mg protein $)^{-1}$; the values represent means of triplicate assays and the respective standard deviations. ND, Activity not detected.

\begin{tabular}{|lcccc|}
\hline \multirow{2}{*}{ Enzyme } & Glucose & \multicolumn{2}{c|}{ Glucose and acetic acid } & \multirow{2}{*}{ Acetic acid } \\
\cline { 2 - 4 } & & 1st phase & 2nd phase & \\
\hline ACS & $0.0374 \pm 0.0035$ & $0.0337 \pm 0.0024$ & $0 \cdot 061 \pm 0.009$ & $0 \cdot 146 \pm 0 \cdot 008$ \\
ICL & ND & ND & $0.087 \pm 0 \cdot 012$ & $0 \cdot 181 \pm 0.023$ \\
MDH & $1 \cdot 6000 \pm 0.1200$ & $2 \cdot 6100 \pm 0 \cdot 2800$ & $8 \cdot 350 \pm 0.600$ & $9 \cdot 650 \pm 0.320$ \\
PEPCK & ND & ND & $0.182 \pm 0.010$ & $0 \cdot 327 \pm 0.059$ \\
\hline
\end{tabular}

glucose plus acetic acid (first phase) than in acetic-acidgrown ones, indicating that it was partially subject to glucose repression. Activity of the enzymes isocitrate lyase and phosphoenolpyruvate carboxykinase was found in acetic-acid- but not in glucose-grown cells. In mixed-substrate medium, activity of both these enzymes was only measurable in the second growth phase, after glucose exhaustion, suggesting that neither the glyoxylate cycle nor gluconeogenesis is involved in acetic acid metabolism occurring during the first phase in the presence of glucose. Malate dehydrogenase was also active under all growth conditions tested, the highest values for its activity being found when glucose was absent from the medium. In cells from the first phase of mixed-substrate medium, malate dehydrogenase activity values were slightly higher than those in glucose-grown cells, indicating that the Krebs cycle could be involved in acetic acid metabolism in the presence of glucose. Cells harvested from the first growth phase were also used to determine the kinetic parameters of acetyl-CoA synthetase for acetate $\left[K_{\mathrm{m}} 16 \pm 1.0 \mathrm{mM}\right.$ and $V_{\max }$ $\left.0 \cdot 11 \pm 0.044 \mu \mathrm{mol}(\mathrm{mg} \text { protein })^{-1} \mathrm{~min}^{-1}\right]$. Although the affinity of the enzyme was relatively low, it did not seem to be limiting metabolism since in these cells the intracellular concentration of the acid was high $(117 \mathrm{mM})$. These results reinforced the evidence from the previous section indicating that the acid is metabolized simultaneously with glucose.

In summary, our studies concerning the transport and intracellular metabolism of acetic acid indicated that in $Z$. bailii: (i) acetyl-CoA synthetase is only partially subjected to glucose repression, so in this way and since no significant activity was measurable for phosphoenolpyruvate carboxykinase or isocitrate lyase, acetic acid could be metabolized as an additional energy source and/or in biosynthetic pathways; and (ii) in cells grown in glucose plus acetic acid (first phase), an acetic acid carrier is present but subjected to control by the intracellular acid concentration. In these cells, the activity level of acetyl-CoA synthetase was much lower than that in acetic-acid-grown cells; if the acetic acid carrier was not subject to control by internal acetic acid, the acetyl-CoA synthetase activity level would probably not be sufficient to allow a metabolic flux compatible with the maintenance of intracellular acetic acid at relatively low levels. Thus it appears that in Z. bailii acetic acid membrane transport and the enzyme acetylCoA synthetase could assume particular physiological relevance to the high resistance of yeast to environments containing mixtures of sugars and acetic acid, such as those often present during wine fermentation. Under these conditions, both the membrane transport flux and the intracellular metabolic flux of the acid seem to be regulated in such a way that the intracellular free acetic acid could probably be maintained below the values above which toxic effects may occur.

\section{ACKNOWLEDGEMENTS}

This study was supported by a research grant (contract AIR CT93-0830). F.R. was the recipient of a fellowship from Praxis XXI (Junta Nacional de Investigação Científica). The authors thank D. Schuller for the optimization of cell-free extracts preparation.

\section{REFERENCES}

van den Berg, M. A., Jong-Gubbels, P., Kortland, C. J., van Dijken, J. P., Pronk, J. T. \& Steensma, H. Y. (1996). The two acetyl-CoA synthetases of Saccharomyces cerevisiae differ in respect to kinetic properties and transcriptional regulation. J Biol Chem 46, 28953-28959.

Casal, M. \& Leăo, C. (1995). Utilization of short-chain monocarboxylic acids by the yeast Torulaspora delbrueckii: specificity of the transport systems and their regulation. Biochim Biophys Acta 1267, 122-130.

Cássio, F., Leăo, C. \& van Uden, N. (1987). Transport of lactate and other short-chain monocarboxylates in the yeast Saccharomyces cerevisiae. Appl Environ Microbiol 53, 509-513.

Cássio, F., Côrte-Real, M. \& Leấo, C. (1993). Quantitative analysis of proton movements associated with the uptake of weak carboxylic acids. The yeast Candida utilis as a model. Biochim Biophys Acta 1153, 59-66.

Furhman, G. F. \& Völker, B. (1992). Regulation of glucose transport in Saccharomyces cerevisiae. J Biotechnol 27, 1-15.

Grenson, M. (1992). Amino acid transporters in yeast: structure, 
function and regulation. In Molecular Aspects of Transport Proteins, pp. 219-245. Edited by J. J. H. H. M. De Pont. Amsterdam: Elsevier.

Horák, J. (1986). Amino acid transport in eucaryotic microorganisms. Biochim Biophys Acta 864, 223-256.

Huismank, L. A. \& Hansen, T. A. (1982). Induction of isocitrate lyase in Escherichia coli. In Sourcebook of Experiments for the Teaching of Microbiology, pp. 138-144. Edited by S. B. Primrose \& A. C. Wardlaw. London: Academic Press.

Leão, C. \& van Uden, N. (1986). Transport of lactate and other short-chain monocarboxylates in the yeast Candida utilis. Appl Microbiol Biotechnol 23, 389-393.

Perea, J. \& Gancedo, C. (1982). Isolation and characterization of a mutant of Saccharomyces cerevisiae defective in phosphoenolpyruvate carboxykinase. Arch Microbiol 132, 141-143.

Postma, E., Verduyn, C., Scheffers, W. A. \& van Dijken, J. P. (1989). Enzymatic analysis of the Crabtree effect in glucose- limited chemostat cultures of Saccharomyces cerevisiae. Appl Environ Microbiol 53, 468-477.

Sousa, M. J., Miranda, L., Côrte-Real, M. \& Leâo, C. (1996). Transport of acetic acid in Zygosaccharomyces bailii: effects of ethanol and their implications on the resistance of the yeast to acidic environments. Appl Environ Microbiol 62, 3152-3157.

van Uden, N. (1967). Transport-limited fermentation and growth of Saccharomyces cerevisiae and its competitive inhibition. Arch Microbiol 58, 155-168.

Witt, J., Kronau, R. \& Holzer, H. (1966). Repression von alkoholdehydrogenase, malatdehydrogenase, isocitratlyase und malatsynthase in hefe durch glucose. Biochim Biophys Acta 118, 522-537.

Received 24 June 1997; revised 14 October 1997; accepted 7 November 1997. 